\title{
Inflection Points on Some S-Shaped Curves
}

\author{
Anna M. Michałowska-Kaczmarczyk1, Tadeusz Michałowski², Agustin G. Asuero ${ }^{3}$ \\ ${ }^{1}$ Department of Oncology, The University Hospital in Cracow, Cracow, Poland \\ ${ }^{2}$ Faculty of Engineering and Chemical Technology, Technical University of Cracow, Cracow, Poland \\ ${ }^{3}$ Department of Analytical Chemistry, The University of Seville, Seville, Spain \\ Email: michalot@o2.pl
}

Received 9 December 2013; revised 9 January 2014; accepted 15 January 2014

Copyright (C) 2014 by authors and Scientific Research Publishing Inc.

This work is licensed under the Creative Commons Attribution International License (CC BY).

http://creativecommons.org/licenses/by/4.0/

(c) (i) Open Access

\section{Abstract}

This paper refers to inflection point-the fundamental property of $S$-shaped curves. In this paper, the inflection points are related to $\mathrm{pH}$ titration curve $\mathrm{pH}=\mathrm{pH}(V)$, and to the curve $\sigma=\sigma(\mathrm{pH})$ involved with surface tension, $\sigma$.

\section{Keywords}

\section{pH Titration; Surface Tension}

\section{Introduction}

This paper recalls the well-known property of different functions represented by the curves with sigmoidal shape (S-shape) [1], involved with inflection (inf) point. An inflection point is the point on $2 D$ plane where the curvature of the curve changes direction. The S-shape is characteristic, among others, for potentiometric titration curves [2]. Different methods of equivalence (eq) point determination are based on location of the inflection point on the curves $\mathrm{pH}=\mathrm{pH}(V)$ or $E=E(V)$, where $E$-potential, $V$-volume of titrant added. The inflection points are registered also in different physicochemical studies.

Generalizing, we refer to a monotonic function $\mathrm{y}=y(x)$. The inflection point $\left(x_{\text {inf }}, y_{\text {inf }}\right)$ corresponds to maximal slope $|\eta|$, where

$$
\eta=\frac{\mathrm{d} y}{\mathrm{~d} x}=\frac{1}{\mathrm{~d} x / \mathrm{d} y}
$$

Applying the relation

$$
\frac{\mathrm{d}^{2} x}{\mathrm{~d} y^{2}} \cdot\left(\frac{\mathrm{d} y}{\mathrm{~d} x}\right)^{3}+\frac{\mathrm{d}^{2} y}{\mathrm{~d} x^{2}}=0
$$

at the inflection point on the curve $y=y(x)$ we have

How to cite this paper: Michałowska-Kaczmarczyk, A.M., Michałowski, T. and Asuero, A.G. (2014) Inflection Points on Some S-Shaped Curves. Journal of Analytical Sciences, Methods and Instrumentation, 4, 27-30. 


$$
\frac{\mathrm{d}^{2} y}{\mathrm{~d} x^{2}}=0
$$

and then at $\mathrm{d} y / \mathrm{d} x \neq 0$ we get

$$
\frac{\mathrm{d}^{2} x}{\mathrm{~d} y^{2}}=0
$$

It means that the maximal slope is equivalent with the relation (4) valid for the inverse function $x=x(y)$. This property is important for $\mathrm{pH}$ titration curves; namely, the functions $V=V(\mathrm{pH})$ assume relatively simple form [3].

In this paper, we refer to a simple acid-base titration $(y=\mathrm{pH}, x=V)$, and to the relationship $\sigma=\sigma(\mathrm{pH})$ for surface tension $(y=\sigma, x=\mathrm{pH})$.

\section{Relation between Equivalence and Inflection Points in pH Titration}

The main task of titration made for analytical purposes is the estimation of the equivalence volume $\left(V_{e q}\right)$. Let us consider the simplest case of titration of $V_{0} \mathrm{~mL}$ of $C_{0} \mathrm{~mol} / \mathrm{L} \mathrm{HCl}$ as titrand (D) with $V \mathrm{~mL}$ of $C \mathrm{~mol} / \mathrm{L} \mathrm{NaOH}$ as titrant (T). At $V=V_{e q}$, the fraction titrated

$$
\Phi_{e q}=\frac{C \cdot V_{e q}}{C_{0} \cdot V_{0}}=1
$$

i.e., $C V_{\text {eq }}=C_{0} V_{0}$. In this $\mathrm{D}+\mathrm{T}$ system, the titration curve $V=V(\mathrm{pH})$ has the form

$$
V=V_{0} \cdot \frac{C_{0}-\alpha}{C+\alpha}
$$

where

$$
\alpha=\left[\mathrm{H}^{+}\right]-\left[\mathrm{OH}^{-}\right]=10^{-\mathrm{pH}}-10^{\mathrm{pH}-p K_{W}}, p K_{W}=-\log K_{W}, K_{W}=\left[\mathrm{H}^{+}\right]\left[\mathrm{OH}^{-}\right]
$$

To facilitate the calculations, it is advisable to rewrite (6) into the form

$$
V_{0}+V=V_{0} \cdot\left(C_{0}+C\right) \cdot \frac{1}{C+\alpha}
$$

From (5) and (6) we get

$$
\alpha=C \cdot \frac{V_{e q}-V}{V_{0}+V}=C \cdot z, \text { where } z=\frac{V_{e q}-V}{V_{0}+V}
$$

From (8)

$$
\begin{gathered}
u=\frac{\mathrm{d}\left(V_{0}+V\right)}{\mathrm{dpH}}=\ln 10 \cdot V_{0}\left(C_{0}+C\right) \cdot(C+\alpha)^{-2} \cdot\left(\left[\mathrm{H}^{+}\right]+\left[\mathrm{OH}^{-}\right]\right) \\
\frac{\mathrm{d} u}{\mathrm{dpH}}=\frac{\mathrm{d}^{2} V}{\mathrm{dpH}^{2}}=-(\ln 10)^{2} \cdot V_{0}\left(C_{0}+C\right)\left(\alpha \cdot(C+\alpha)^{-2}-2 \cdot\left(\left[\mathrm{H}^{+}\right]+\left[\mathrm{OH}^{-}\right]\right)^{2} \cdot(C+\alpha)^{-3}\right)
\end{gathered}
$$

Setting $\mathrm{d}^{2} V / \mathrm{dpH}^{2}=0$ and writing $\left(\left[\mathrm{H}^{+}\right]+\left[\mathrm{OH}^{-}\right]\right)^{2}=\alpha^{2}+4 K_{W}$, from (10) we get, by turns,

$$
\begin{aligned}
& \alpha(C+\alpha)-2\left(\alpha^{2}+4 K_{W}\right)=0 \\
& \alpha^{2}-C \cdot \alpha+8 K_{W}=0 \\
& z^{2}-z+8 K_{W} / C^{2}=0
\end{aligned}
$$

From (11) we obtain for $z=z_{\text {inf }}$

$$
z_{\text {inf }}=\frac{1}{2} \cdot\left(1-\sqrt{1-32 \cdot K_{W} / C^{2}}\right)=8 K_{W} / C^{2}+\left(8 K_{W} / C^{2}\right)^{2}+\cdots
$$

and then for $V=V_{\text {inf }}$ [3] [4] 


$$
V_{e q}-V_{i n f}=z_{i n f} \cdot V_{0} \cdot \frac{1+C_{0} / C}{1+z_{i n f}}
$$

Analogous result can be obtained for titration of $V_{0} \mathrm{~mL}$ of $C_{0} \mathrm{~mol} / \mathrm{L} \mathrm{NaCl}$ with $V \mathrm{~mL} \mathrm{AgNO}_{3}$ [5]. Denoting $\left[\mathrm{Ag}^{+}\right]\left[\mathrm{Cl}^{-}\right]=K_{\text {so }}$ we get (13), where [5]

$$
z_{\text {inf }}=\frac{1}{2} \cdot\left(1-\sqrt{1-32 \cdot K_{\text {so }} / C^{2}}\right)
$$

At $p K_{s o}=9.75$ for AgCl, $V_{0}=100 \mathrm{~mL}, C_{0}=10^{-4}$ and $C=10^{-3}$, we get $V_{e q}-V_{\text {inf }}=0.16 \mathrm{~mL}$.

\section{A Comment to Szyszkowski Formula}

Many physicochemical processes are graphically represented by the curves with the sigmoidal shape. In this section, we refer to the function $\sigma=\sigma(\mathrm{pH})$ obtained on the basis of Szyszkowski's empirical formula [6]

$$
\sigma=\sigma_{0}-a \cdot \ln (1+b \cdot[\mathrm{HL}])
$$

expressing the relationship between surface tension $\sigma$ and concentration [HL] of uncharged form HL of an aliphatic fatty acid as a surfactant in aqueous media; $\sigma_{0}$ —surface tension of pure water, $a, b$-constants.

Denoting $[\mathrm{HL}]+\left[\mathrm{L}^{-}\right]=C$ and

$$
K_{1}=\frac{\left[\mathrm{H}^{+}\right]\left[\mathrm{L}^{-}\right]}{[\mathrm{HL}]}
$$

we get, by turns:

$$
\begin{aligned}
& {[\mathrm{HL}]=C \cdot \frac{\left[\mathrm{H}^{+}\right]}{\left[\mathrm{H}^{+}\right]+K_{1}}} \\
& 1+b \cdot[\mathrm{HL}]=\frac{(1+b \cdot C) \cdot\left[\mathrm{H}^{+}\right]+K_{1}}{\left[\mathrm{H}^{+}\right]+K_{1}} \\
& \sigma=\sigma_{0}-a \cdot \ln \left((1+b \cdot C) \cdot\left[\mathrm{H}^{+}\right]+K_{1}\right)+a \cdot \ln \left(\left[\mathrm{H}^{+}\right]+K_{1}\right) \frac{\mathrm{d} \sigma}{\mathrm{d}\left[\mathrm{H}^{+}\right]}=-a \cdot\left(\frac{(1+b \cdot C)}{(1+b \cdot C) \cdot\left[\mathrm{H}^{+}\right]+K_{1}}-\frac{1}{\left[\mathrm{H}^{+}\right]+K_{1}}\right) \\
& u=\frac{\mathrm{d} \sigma}{\mathrm{dpH}}=\left(\frac{\mathrm{d} \sigma}{\mathrm{d}\left[\mathrm{H}^{+}\right]}\right) \cdot\left(\frac{\mathrm{d}\left[\mathrm{H}^{+}\right]}{\mathrm{dpH}}\right)=-\ln 10 \cdot\left[\mathrm{H}^{+}\right] \cdot \frac{\mathrm{d} \sigma}{\mathrm{d}\left[\mathrm{H}^{+}\right]} \\
& =-\ln 10 \cdot a \cdot\left(\frac{(1+b \cdot C) \cdot\left[\mathrm{H}^{+}\right]}{(1+b \cdot C) \cdot\left[\mathrm{H}^{+}\right]+K_{1}}-\frac{\left[\mathrm{H}^{+}\right]}{\left[\mathrm{H}^{+}\right]+K_{1}}\right) \\
& \frac{\mathrm{d}^{2} \sigma}{\mathrm{dpH}^{2}}=-\ln 10 \cdot\left[\mathrm{H}^{+}\right] \cdot \frac{\mathrm{d} u}{\mathrm{~d}\left[\mathrm{H}^{+}\right]} \\
& =(\ln 10)^{2} \cdot a \cdot K_{1} \cdot\left[\mathrm{H}^{+}\right] \cdot\left(\frac{1+b \cdot C}{\left.\left((1+b \cdot C) \cdot\left[\mathrm{H}^{+}\right]+K_{1}\right)\right)^{2}}-\frac{1}{\left(\left[\mathrm{H}^{+}\right]+K_{1}\right)^{2}}\right)
\end{aligned}
$$

Putting $\mathrm{d}^{2} \sigma / \mathrm{dpH}^{2}=0$, from Equation (16) we get $\left[\mathrm{H}^{+}\right] \cdot(1+b \cdot C)^{1 / 2}=K_{1}$, and then

$$
\mathrm{pH}=\mathrm{pH}_{\text {inf }}=p K_{1}+\frac{1}{2} \cdot \log (1+b \cdot C)
$$

From Equation (17) it results that the abscissa $\left(\mathrm{pH}_{\text {inf }}\right)$ corresponding to inflection point does not overlap with $p K_{1}$ value for HL. 


\section{References}

[1] Sigmoid Function. http://en.wikipedia.org/wiki/Sigmoid_function

[2] Greschonig, H. and Glatter, O. (1986) Determination of Equivalence Points of Sigmoidal Potentiometric Titration Curves. Microchimica Acta, 89, 401-409. http://link.springer.com/article/10.1007\%2FBF01207332

[3] Asuero, A.G. and Michałowski, T. (2011) Comprehensive Formulation of Titration Curves for Complex Acid-Base Systems and Its Analytical Implications. Critical Reviews in Analytical Chemistry, 41, 151-187.

[4] Michałowski, T. (1981) Some Remarks on Acid-Base Titration Curves. Chemia Analityczna, 26, 799-813.

[5] Michałowski, T. and Stępak, R. (1985) Evaluation of the Equivalence Point in Potentiometric Titrations with Application to Traces of Chloride. Analytica Chimica Acta, 172, 207-214. http://dx.doi.org/10.1016/S0003-2670(00)82608-2

[6] von Szyszkowski, B. (1908) Experimentelle Studien über kapillare Eigenschaften der wässerigen Lösungen von Fettsäuren. (Experimental studies of the capillary properties of aqueous solutions of fatty acids), Zeitschrift für Physikalische Chemie, 64, 385-414. 